\title{
Justification for Using Scale Models for Impact Response Evaluation of the SST Transportation System
}

\author{
R. E. Berry \\ Transportation Division \\ Sandia National Laboratories \\ Albuquerque. NM 87185
}

\begin{abstract}
The validity of scale model impact evaluation of the SST Transportation System is acceptable based on Dimensional Analysis (Buckingham Pi Theorem) and the work of numerous programs that have evaluated the agreement among dimensional analysis. several different reduced-size models and full-scale impact test data. Excellent accuracy has been demonstrated between scale models and full-scale impact data when collected in conformance with the Buckingham Pi Theorem.
\end{abstract}




\section{Contents}

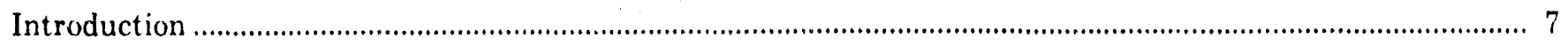

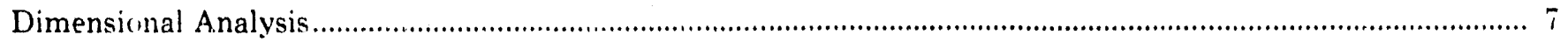

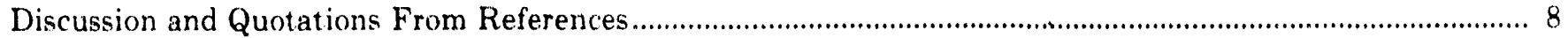

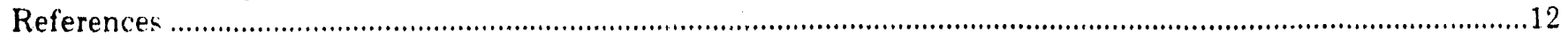




\section{Justification for Using Scale Models for Impact Response Evaluation of the SST Transportation System}

\section{Introduction}

Impact testing of SST trailers is necessary to establish the crash-worthiness of the trailer. Although computer modeling of the trailer can be accomplished for the task of establishing the crash-worthiness of the trailer. the model must be verified with trailer impact data before it will be acceptable for parametric studies of the trailer accidents. Further, the use of full-scale hardware in a full-scale test program would be extremely expensive and time consuming and would reduce the size of the usable fleet from its assigned mission of transporting nuclear materials. The procurement of new trailers for test purposes is prohibitive both in time and cost. Therefore, a library search was conducted to ascertain the feasibility of using replica scale models of the trailer to acquire the needed data. The literature assembled from the search indicate' a world-wide acceptance of scale model test data from replica scale models for the uesign evaluation of mechanical structures. The following discussion gives the approach and justification for the acceptance of scale-model test data to represent the damage sustained by full-scale trailers involved in acciden.s.

The mathematical approach to scale-model test ing has been developed over several years. There are two fundamental approaches commonly used in developing scaling laws to allow the prediction of prototype response by experimentation with scale mod. els. The first method it to describe all the governing equations for the system and manipulate these equations into dimensionless groupings of the primary variables. This, of course, requires a rigorous treatment to produce the governing equations and further rigorous effort to produce the dimensionless parameters. The second method requires a thorough familiarity with the physical phenomena and parameters that govern the system. It requires grouping the variables of interest into dimensionless quantities by applying the technique of dimensional analysis, e.g., the work of Buckingham (1915). References 1-5 and
9-14 all are examples of the use of dimensional analysis in producing, generally speaking, scale models or replica models of the prototype system. Further, References 6.8 are text books on similitude theory, similitude in engineering, and dimensional analysis. Each has reference to the Buckingham $\mathrm{Pi}$ Theorem.

\section{Dimensional Analysis}

The Buckingham Pi Theorem is the basis for most dimensional analyses and asserts that any complete physical relationship may be expressed in terms of a set of independent dimensionless products com. posed of the relevant physical parameters. They form a relationship between pressures, strains, and time to describe material response and, for modeling purposes, are represented by $N$ constants $C_{i}$ with dimensions (pressure) $a_{i}$, (time) $b_{i}$. The number of terms, $N$, and the exponents $a_{i}$ and $b_{i}$, are characteristic of the material considered. A mathematical statement of the $\mathrm{Pi}$ theorem might be the following:

If the equation $\mathrm{F}\left(\mathrm{X}_{1}, \mathrm{X}_{22} \ldots \mathrm{X}_{\mathrm{N}^{\prime}}\right)=0$ is complete, then the solution has the form $\mathrm{F}\left(\mathrm{II}_{1}, \mathrm{Il}_{2} \ldots\right.$ $\left.\Pi_{N-k}\right)=0$ where the $\mathrm{Pi}(\Pi)$ terms are independent products of the parameters $\mathrm{X}_{1}, \mathrm{X}_{2}, \ldots$, etc. and are dimensionless in the fundamental dimensions. ${ }^{3}$

The number of pi terms in the solution equation is less than the number of parameters by a factor $K$. Usually $K$ equals the number of basic dimensions describing the $\mathrm{X}_{\mathrm{i}}$ terms; e.g., length, mass, time comprise one choice. In an impact problem, the nondimensional parsmeters form a relationship between pressure, strains and time $(K-3)$ to describe material response and for modeling purposes are represented by $N$ constants $C_{i}$, with dimensions (pressure) $a_{i}$, (time) $b_{i}$. The number of terms, $N$, and the exponents $a_{i}$ and $b_{i}$ are characteristic of the material considered. 
$\Pi_{i}=\frac{L}{C_{i}} p^{a} \cdot\left[\frac{L}{V}\right]^{b_{i}} \quad: \quad i=1 \rightarrow N$

The terms pertinent to impact include the following representative list of characteristic parameters:

$\mathrm{L}$ - linear dimension

$\sigma$-- pressure or stress

$\rho$ - density

e - energy

$v$ - velocity

$\mathrm{m}$ - mass

$f$ - applied force

$d$ - space coordinate (deformation)

$\mathrm{t}$ - time

The number of pertinent terms $(\mathrm{N})$ minus the number of fundamental dimensions $(K=3)$ constitutes a complete set of pi (II) teirms $(N-K=6 i$.

$\mathrm{II}_{\mathrm{N}-1}=\mathrm{F} / \sigma \mathrm{L}^{-}$

$\mathrm{Il}_{\mathrm{N}-\mathrm{Z}}=\mathrm{m}^{2} / \sigma \mathrm{L}^{3}$

$\Pi_{\mathrm{X} .: 3}=\mathrm{e} / \mathrm{TL}^{: 3}$

$\mathrm{Il}_{1 .+4}=\mu \mathrm{s}^{\prime \prime} / \sigma$

$\mathrm{Il}_{\mathrm{\lambda}, \mathrm{i}}=\mathrm{d} / \mathrm{L}$

$\mathrm{Il}, \mathrm{H}=\mathrm{vt} / \mathrm{L}$

Modeling requires the reduction of the linear dimension of prototype to the scale model and still, by proper manipulation of the test conditions. maintain constant values of pi (II) for the prototype and the scale model. If this can be done. then the data obtained from scale modal impact tests will be repre. sentative of the prototype system response. To produce a replica scale model, it is most desirable to use the same material in both the prototype and the scale model and thereby alleviate the necessity of adjusting the material parameters $\left(\mathrm{II}_{i}\right)$ when dissimilar materials are used. The stress $(\sigma)$ and the density $(\rho)$ are constant between the prototype and the model: therefore. to maintain the dimensionless characteristic of the $\left(\mathrm{II}_{\mathrm{i}}\right)$ terms requires that $(\mathrm{v} / \mathrm{L})$ remain constant while $\left(\Pi_{N_{-}+4}\right)$ requires that $\left(\rho v_{2} / \sigma\right)$ remain constant-a seemingly impossible task since $(\rho)$ and $(\sigma)$ are constants and $(L)$ varies between model and prototype. However, since $(\mathrm{v} / \mathrm{L})$ is the strain rate, and experiments have shown that for metals at high strain rates, the material strength is relatively constant, the assumption is made that $(\mathrm{v} / \mathrm{L})$ can be neglected in the response of metal structures. ${ }^{5,14,18}$ If the motion of the scale-model structure is horizontal and the static gravitational deformations are small, there is negligible effect from failing to scale gravity properly. How- ever, when testing of scale models induces significant vertical acceleration, then the acceleration due to gravity may become important. Reference 5 discusse: the potential for adjusting the test conditions for an automobile rollover where vertical acceleration is quite low and gravity becomes significant.

With the assumptions that the strain rate is constant and gravity has no effect on horizontal impacts, we can establish the relationship between the prototype and the scale model. Where $(n)$ is the scaling factor, the relationships between the prototype variabies and the scale model variables are shown in the following table $(n<1)$.

\begin{tabular}{|c|c|c|}
\hline Variable & Prototype & Model \\
\hline Length & $\mathrm{L}$ & $\mathrm{Ln}$ \\
\hline Deformation & $d$ & $d$ \\
\hline Strain & $\epsilon$ & $t$ \\
\hline Stress & $\sigma$ & $\sigma$ \\
\hline Time & $t$ & $\mathrm{tn}$ \\
\hline Velocity & $v$ & $r$ \\
\hline Force & $\mathrm{F}$ & Fn:" \\
\hline Energy & $\mathrm{e}$ & $e n^{-1}$ \\
\hline Mass & $\mathrm{m}$ & $m n^{3}$ \\
\hline Acceleration & $\mathrm{a}$ & $\mathrm{a} / \mathrm{n}$ \\
\hline Density & $\rho$ & $"$ \\
\hline Elastic Modulus & $\mathrm{E}$ & $\mathrm{E}$ \\
\hline Strain Rate & $\epsilon$ & $\mathrm{d} / \mathrm{n}$ \\
\hline Acceleration of Gravity & $\mathrm{g}$ & $\mathrm{g} / \mathrm{n}$ \\
\hline
\end{tabular}

Based on the above scaling relationships and the following assumptions, a geometrically reduced scale model of the same material as the prototype will incur damage that is geometrically similar to the prototype.

1. Model and prototype are geometrically similar.

$\therefore$ Model and prototype are constructed of the same material.

3. Strain Rate effects are negligible.

4. There are no gravitational effects on horizontal impact testing ( $a \gg g$ ).

5. Coefficients-of-friction for model, prototype and targets are similar.

The secret to dimensional analysis is the realization that in equivalent systexns, individual parameters can vary, but the pi terms are invariant.

\section{Discussion and Quotations From References}

Scale model impact test data, when used to evaluate the damage to the full-scale prototype, has been 
proved by the established theory and by actual comparison of scale model and full-scale prototype impact test data. The foundation of the theory for scale modeling has been discussed above, and the applicability of scale-model data to the prototype is illustrated by the following quotations. Scale-model impact test data is applicable to the damage evaluation of the full-scale prototype structure. In general, these quotations demonstrate a simple statement of fact:

\section{"It works and it's cheap."}

Ref. 2. Scaling Laws for Fuel Capsules Subjected to Blast Impact and Thermal Loading (1/4 scale)

Quote: "The following general scaling laws have been shown to apply to fuel capsules testing.

Model and prototype constructed of the same materials:

1. The model must be geometrically similar to the prototype:

2. Surface tractions must be identical in magnitude and direction at homologous points at the same geometrically scaled :imes:

i. 'Inct applicable to impactl' temperature ...

4. Strain rate effects are negligible.

If conditions 1 through 4 are satisfied, transient and final stresses and strains at homologous points in both model and prototype are identic?. Deflections scale as the geometrical scale factur."

Ref. 3. (In the us "if modeing in a Structural Response Problem (1/4 scale)

The reference discusses the analytical approach and the experimental testing of both models and prototypes as verification of the analytical work.

Quote: "On the basis of the above test results, modeling was verified for the design of an impact-resistant container. Deviations from expected results either were in the realm of experimental accuracy or could be explained by the nonsimilarity of targets. Since the large deformations experienced in the modeling tests were greater than those expected in the design program, and all other aspects of the modeling appeared valid, the design program could be based on a large number of small model tests."

Ref. 4. Analysis, Scale Modeling and Full-íscale Tests of a Truck Spent Nuclear Fuel Shipping System in High Velocity Impacts Against a Rigid Barrier
This report brings together in a concise, comprehen. sive manner a description of the mathematical analysis, scale modeling and results of the full scale tests (1/8 scale).

Quote: "Scale modeling is a very practical way of predicting damage to shipping casks in extremely severe impacts at skeved angles or onto irregular surfaces. Construction and testing of scale models is relatively inexpensive and straightforward."

"Somewhat simplified (adequate) scale models used in impact tests will accurately predict the response of the new design." Testing was performed on weakened cask tiedown system and resulted in greater damage to the cask under nearly the same impact conditions.

Quote: "This investigation revealed that the cask tiedown is a sensitive parameter in the system impact response. In order to take advantage of the significant energy absorption capability of the trailer, the tiedowns must be sufficiently strong to hold the cask as the trailer structure crushes. Thus, it is believed that the trailer and tiedowns should be an integral and balanced design."

Ref. 5. Scale Modeling of leticle Crashes - Techniques, Applicability, and Accuracy; Cost Effecticeness

The utility of scale model experiments for crash. worthiness (automotive) research is examined $(1 / 8$, $1 / 6,1 / 4,1 / 3$ scale).

Quote: "The 2Al full-scale and 1/4-scale experiments illustrate the key conclusion of this paper: scale models can be used to study the response of complex structures."

"Accelerations, displacements, fractures, and buck. ling observed in the full-scale experiment were repro. duced in the scale model with considerable accuracy."

\section{Cost Savings}

Quote: "For individual crash tests, we conclude that:

- Small-scale models can be built and crash tested in a laboratory for between one-third and onefourth the cost of equivalent full-scale tests. (See Figure 4.)

- The optimum scale factor in terms of cost effectiveness and convenience in testing is between $1 / 6$ and $1 / 4$.

- Model tests take less than one-third the time to perform as full-scale tests; the time saving is 
even greater if model fabrication time is considered."

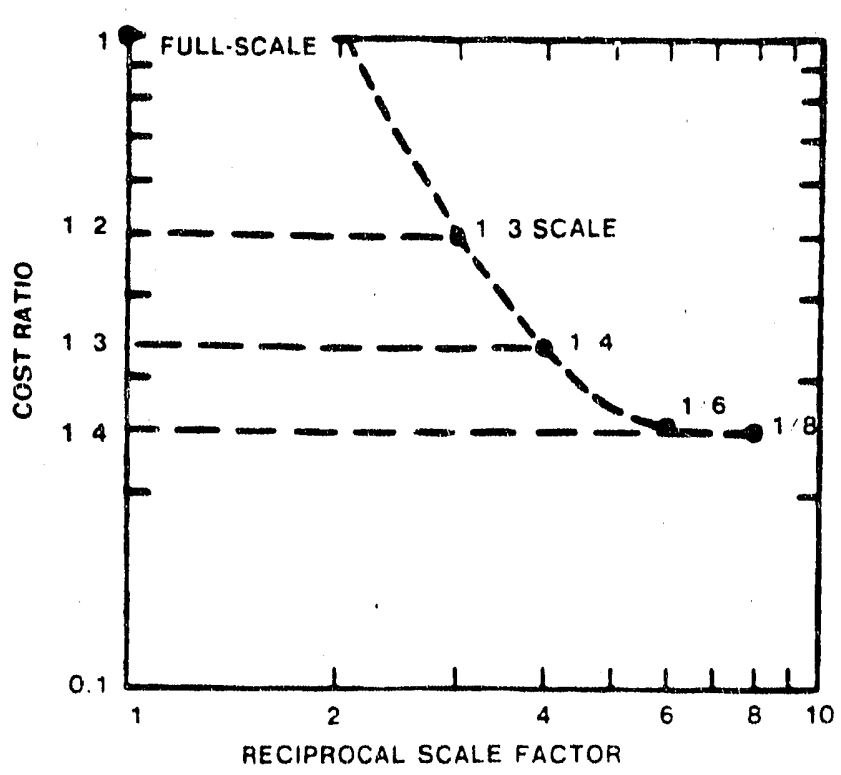

Figure 4. Scale model cost saving per test (fabrication and testing)

Ref. 9. Impact Tests on Scale Medel of a Shoct Absurber for a LWh spent Fuel Transport l'ackaking! (1/9, 1/6, 1/2 scalel

Quote: "The experimental results and the analysis carried out confirmed that it is possible to obtain useful design informarion for this type of shock absorber by means of reduced-scale model testing with evident economical and practical advantages."

Ref. 11. DOE/PNC Joint J'rugram (In Transportation Technolut:: (1/4 scale)

Qucte: "Before full-scale testing of the transport system was undertaken. structural analysis and scale model testing were performed to evaluate the re. sponse of the system under the specified impact condition."

"The ultimate breaking strength of the fifth-wheel connection is another item that could only be estimated; it was found to be a parameter that significantly affects results."

"The structural analysis work relating to impact of the system onto a rigid barrier (based on analytical and physical scale models) indicated that the vehicular system would be seriously damaged but the cask would remain undamaged on the trailer structure. These results were confirmed by a full-scale impact test demonstrating the usefulness of these analysis techniques to a very satisfactory degree."

Ref. 13. Scale Model Turbine-Missile-Casing Impact Tests (1/5 scale)

Quote: "The objective was to examine the accuracy and usefulness of scale model testing for studying turbine-missile impact on steel struc tures."

"With the missile oriented differently in each of two scales model tests, the structural response observed in the corresponding full-scale tests was duplicated with remarkable accuracy."

Ref. 14. Experimental Studies of Dynamic Impact Re' sponse with Scale Models of Lead Shielded Radioartive Materia! Shipping Container (1/8, 1/4, 1/2 scale)

Quote: "The objectives of the study were (1) to determine the success with which scale models could be used to determine the dynamic structural respon'se of radioactive material shipping containers for safety and environmental control assessment, (2) ... etc."

"The interpretation of the data appears to substantiate the assumptions and predictive scaling law's that were developed using dimensional analysis techniques."

Ref. 15. Analysis-Scale Modeling and Full-Scale Test of a Railcar and Spent Nuclear Fuel Shipping ('ask in a High Velocity Impact Against a Rigid Barrier (1/8 scale)

Quote: "Both the mathematical analysis and the scale model tests were able to predict, with a reasrnable degree of accuracy, the response of a complex rail spent-nuclear-fuel-shipping system involved in an extremely severe accident."

Ref. 16. Analysis, Scale Modeling, and Full-Scale Tests of Lou Level Nuclear Waste Drum Response to Accident Environments (1/8, 1/4 scale)

Quote: "Agreement between the scale models and the full-scale single drum impact tests was excellent when the data was compared in terms of the $d / D$ parameter."

Ref. 17. Experimental and Analytical Studies on the Drop-Impact Test with Lead-Shielded Scale Model Radioactive Material Shippi "Casks. 
Quote: "To evaluate impact behavior of these models, deformation, acceleration and dynamic strain were measured."

“...(2) scaling laws and techniques for drop impact test were discussed and verified with the above tests. As a consequence, it appears possible to predict the dynamic response of casks with scale model tests within a certain limit of scaling down, and the limit is likely about $1 / 4$ scale."

Ref. 18. The Lise of Scale Models in Impact Testing $(1 / 8,1 / 4,1 / 2$ scale $)$
Quote: "Impact behavior of Magnox flasks may be conveniently investigated through the use of scale models. Theory, component testing and model flask testing at various scales have confirmed that identifiable non-scalable variables do not significantly affect the behavior of models over a scale range of eight."

"Accurate reproduction of relevant details and careful experimental control are necessary to achieve good scaling of localized parameters." 


\section{References}

'W. E. Baker, et al, Similarity' Mcthods in Engineering Dynamics Theory and Practice of Scalc Modeling. Spartan Books, 1973.

'T. A. Duffey, Scaling Laus for Fuel Capsules subjected to Blast Impact and Thermal Loading, SC-RR-70134. Sandia Laboratories, May 1970.

${ }^{3} \mathrm{D}$. E. McGovern, et al, On the Use of Modeling in Structural Response Problem, SC-RR-70-880, Sandia Laboratorits, March 197:

${ }^{4}$ M. Huerta, Analy'sis, Scale Modeling, and Full-Scale Tests of a Truck Spent Nuclear Fuel Shipping System in High Velocity Impact Against a Rigid Barrier, SAND77. 0270, Sandia Laboratories, April 1978.

${ }^{5}$ B. S. Holms, et al, Scale Modeling of Vehicle Crashes - Techniques, Applicability, and Accuracy; Cost Effectiveness. Poulter Laboratory, Stanford Research Institute, 1974 .

"y. .J. Skengland. Similitude Theors and Applications, International Textbook Co.. 1967.

G. Murphy, Similitude in Enginering. Ronald Press Co.. 1950

"H. L. Langhaar. Dimensimal Analysis and Theory' of Mod is, John Wiley d: Suns Inc.. 1951.

'1). Aquaro. (i. Forasassi. Impart. Tests on Scale Model of a Shock Aburber for a LWR Spent Fuel Trans. port Packaging. Pisa Lniversity (Italy) Dipartinanto di Costruzioni Neccaniche e Nucleari. 29 August 1983.

"'M. M. Madsen and W. L. Uncapher, Design Verification Testing. SAND84.0559C, 1989.

"M. Kuho, et al. Power Reactor and Nuclear Fuel Development Corporation. Tokyo, Japan: H. R. Yoshimura. et al. Sandia National Laboratories. Albuquerquie. NM: M.
Huerta, et al, Southwest Engineering Associates, Albuquerque, NM, DOE/PNC Joint Programme on Transportation Technology, IAEA-SM-286-96, 1983.

'-R. J. Burian, et al, Validity of Scale Modeling for Large Deformations in Shipping Containers, BMI 2040, Battelle Columbus Labs, Ohio, 19 October 1979.

${ }^{13} \mathrm{C}$. M. Romander, et al, Scale Model Turbine-MissileCasing Impact Tests. EPRI-NP-2742, SRI International, Menlo Park, California, January 1983.

${ }^{14} \mathrm{R}$. A. Robinson, et al, Experimental Studies of $D_{y}$ namic Impact Response with Scale Models of Lead Shielded Radioactive Material Shipping Containers, BMI 2001, Battelle Columbus Labs, 29 September 1978.

${ }^{15}$ M. Huerta, Analysis Scale Model and Full-Scale Test of a Railcar and Spent Nuclear Fuel Shipping Cask in a High Velocity Impact Against a Rigid Barrier, SAND78. 0458. Sandia National Labs, January $198:$.

${ }^{16} \mathrm{M}$. Huerta, et al, Analysis, Scale Modelling and Full-Sicale Tests of a Lou Level Nuclear Waste Drum Response to Accident Environments, SAND80-2517, Sandia National Laboratories, January 1983.

17 Y. Kanae, et al, Experimental and Analytical Studies on the Drop-Impact Test with Lead-Shielded Sicale Model. Radioactive Material Shipping (asks, Mechanical Engineering Laboratory, Agency of Industrial Science and Technology, Ministry of International Trade and Industry. Ja. pan.

"rP. J. Donllan, et al. The l'se of Scale Model in Impact Testing, One Arup and Partners. Consulting Engineers.

${ }^{14}$ E. P. S. Tufton, Horizontal Impact Testing of Quarter Scale Flasks L'sing Masonry Targets. One Arup and Partners. Consulting Engineers.

2'J. H. Barnfield, et al. Demonstration Drop Test, Generation Development and Construction Division CEGB. 


\section{References}

'W. E. Baker, et al, Similarity Methods in Engineering Dynamics Theory and Practice of Scale Modeling. Spartan Books, 1973.

'T. A. Duffey, Scaling' Law's for Fue! Capsules subjected to Blast Impact and Thermal Loading, SC-RR-70134, Sandia Laboratories, May 1970.

"D. E. McGovern, et al, On the Use of Modeling in Structural Response Problem, SC-RR-70-880, Sandia Laboratories, March 1971.

${ }^{4}$ M. Huerta, Analysis, Scale Modeling, and Full-Scale Tests of a Truck Spent Nuclear Fuel Shippin: System in High Velocity' Impact Against a Rigid Barrier, SAND77. 0270, Sandia Laboratories, April 1978.

'B. S. Holnus, et al, Scale Modeling of Vehicle Crashes - Techniques, Applicability, and Accuracy; Cost Effectiveness. Poulter Laboratory. Stanford Research Institute 1974

"V. J. Skogland, Similitude Theory' and Applications, International Textbook Co., 1967.

'G. Murphy, Similitude' in Engincering. Ronald Press Co.. 1950)

'H. L. Langhaar, Dimensional Analysis and Theory' of Mudels. Juhn Wiley d Sons Inc.. 1951.

"D. Aquaro, G. Forasassi. Impact Test" on Scale Model of a Shock Absorter for a l.WR Spent Fuel Trans. purt Packaging. Pisa University (Italy) Dipartinanto di Custruzioni Meccaniche e Nucleari, 29 August $198:$

"M. M. Madsen and W. L. Uncapher. Drighn Verification Testing. SAND89-01599C, 1989

"M. Kuho, et al, Power Reactor and Nuclear Fuel Development Corporation. Tokvo, Japan; H. R. Yoshimura. et al. Sandia National Laboratories. Albuquerque. NM: M
Huerta, et al, Southwest Engineering Associates, Albuquerque. NM, DOE/PNC Joint Programme on Transportation Technology, IAEA-SM-286-96, 1983.

"R. J. Burian, et al, Validity of Scale Modeling for Large Deformations in Shipping Containers, BMI 2040, Battelle Columbus Labs, Ohio, 19 October 1979.

${ }^{13}$ C. M. Romander, et al, Scale Model Turbine-Missile* Casing Impact Tests, EPRI-NP-2742, SRI International, Menlo Park, California, January 1983.

${ }^{14} \mathrm{R}$. A. Robinson, et al. Experimental Studies of $D_{y}{ }^{\prime-}$ namic Impact Response with Scale Models of Lead Shielded Radioactive Material Shipping Containers, BMI 2001, Battelle Columbus Labs, 29 September 1978.

${ }^{15}$ M. Hueria, Analysis Scale Model and Full-Scale Test of a Railcar and Spent Nuclear Fuel Shipping Cask in a High Velocity Impact Against a Rigid Barrier, SAND780453, Sandia National Labs, January 1983.

${ }^{16} \mathrm{M}$. Huerta, et al, Analysis, Scalt' Modelling and Full-Scale Tests of a Low Level Nuclear Waste Drum Response to Accident Environments, SAND80-2517, Sandia National Laboratories, January 1983.

${ }^{17}$ Y. Kanae, et al, Experimental and Analytical Studies on the Drop-Impact Test with Lead-Shielded Scale Model, Radioactive Material Shipping Casks, Mechanical Engineering Laboratory, Agency of Industrial Science and 'Tech. nology, Ministry of International Trade and Industry, dapan.

${ }^{14} \mathrm{P}$. J. Donllan, et al, The Use of Scale Medels in Impact Testing, One Arup and Partners. Consulting Engi. neers.

"E. P. S. Tufton, Horizontal Impact Testing of Quar" ter Scale Flasks Using Masonry Targets, One Arup and Partners, Consulting Engineers.

${ }^{21} \mathrm{~J}$. H. Barnfield, et al, Demonstration Drop Test. Generation Development and Construction Division CEGB. 

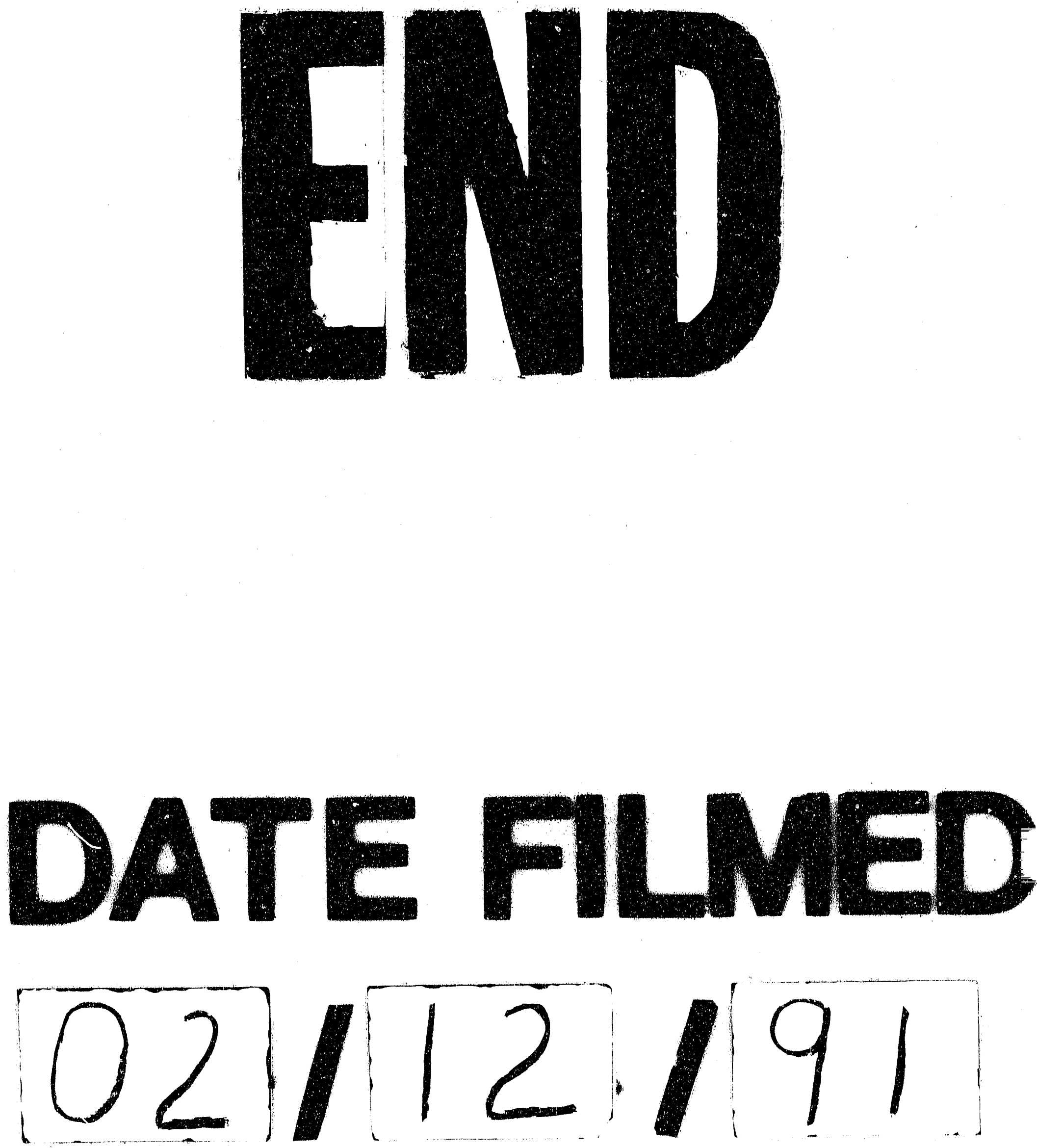

F... 
